\title{
Escrito de un monje a su amigo en la capital
}

E. Th. A. Hoffmann

Introducción, traducción y notas de Gabriel D. Pascansky

Instituto de Filología y Literaturas Hispánicas "Dr. Amado Alonso" (UBA)

gpascansky@filo.uba.ar

Fecha de recepción: 31/3/2020.

Fecha de aceptación: 10/6/2021.

\section{Introducción}

Durante el carnaval de febrero de 1802 en Posen, ciudad ocupada por Prusia tras la segunda partición de Polonia en 1793, circularon unas caricaturas en las que se ridiculizaba a personalidades de la alta sociedad local y la aristocracia militar gobernante. El autor de los dibujos satíricos era E.Th.A. Hoffmann, que había llegado a esta ciudad dos años antes desde Berlín, para ocupar un cargo de funcionario judicial. Luego de la risa general y del escándalo, las autoridades llevan el asunto ante el rey, se inician las investigaciones, los procesos y los arrestos. La participación de Hoffmann es evidente, y en marzo se ordena su traslado a los tribunales de Płock, en donde permanecerá durante dos años hasta lograr un nuevo y venturoso traslado a Varsovia. La pequeña y lejana ciudad de Płock (al sudeste de Posen, en la profundidad de los territorios polacos ocupados por Prusia), que contaba entonces con 3000 habitantes (Berlín, en la misma época, tenía alrededor de 200 mil), faltaba todo estímulo cultural, no se podía pensar en conciertos, funciones de teatro u ópera, las revistas y libros alemanes no llegaban y había que hacérselos enviar (cf. Safranski, 1984). ${ }^{1}$ Hoffmann, que en estos años todavía veía continuamente frustradas sus múltiples aspiraciones artísticas (literarias y, sobre todo, musicales), describe en reiteradas ocasiones su estancia en esta ciudad como un exilio forzado en un lugar desértico; el 17 de octubre de 1803 anota en su diario:

1 En general, hasta que se convierte en escritor, y sobre todo para el período de Płock, se cuenta con poca información sobre la vida de Hoffmann. Las principales fuentes que tenemos son sus cartas y diarios, valorizados recientemente por la crítica a partir de la edición de Deutscher Klassiker de las obras completas de Hoffmann. Cabe destacar también la biografía de Hoffmann escrita por Rüdiger Safranski (1984), uno de los primeros en aprovechar la importancia de aquel corpus autobiográfico. 
¡He trabajado todo el día! ¡Ah! Me convierto cada vez más en funcionario... Quién lo hubiera pensado hace tres años... La musa se escapa... iEl polvo de las actas oscurece y enturbia el panorama! El diario se torna curioso, porque es la prueba de la miseria monstruosa en la que aquí me hundo... iA dónde fueron mis proyectos!, ¿a dónde mis bellos planes para el arte? $(\mathrm{SWI}, 336)^{2}$

En este contexto adverso se publica el primer texto de Hoffmann, el "Escrito de un monje a su amigo en la capital”, en la revista berlinesa Der Freimüthige. A fines de octubre, cuando recibe el ejemplar de la revista, el autor manifiesta en su diario la felicidad por el debut literario y un optimismo sobre su futuro no exento de ironía: "miré la hoja veinte veces con la mirada dulce y cariñosa de la alegría paterna. ¡Aspectos felices para la carrera literaria! Ahora debe ocurrir algo divertido" (ibíd.). La aparición de este ensayo anacrónico, sin embargo, no constituye bajo ningún criterio un inicio de carrera literaria: en primer lugar, porque se trató de una contribución única y no remunerada; en segundo lugar, porque habrían de pasar cinco años hasta la publicación de su siguiente texto (una reseña musical impresa sin su consentimiento). Además, recordemos que todavía hasta mediados de la década de 1810, los esfuerzos artísticos de Hoffmann se dirigen principalmente a la composición musical. El inicio de su carrera literaria propiamente dicha recién puede fecharse en 1809, con la publicación de "El caballero Gluck", su primer cuento, y el comienzo de su colaboración como crítico musical en la Allgemeine musikalische Zeitung, o en 1814, con el éxito de su primer libro, Fantasías a la manera de Callot.

El “Escrito de un monje”, por otra parte, más allá de su lugar singular como texto primigenio y olvidado de un gran escritor, tiene un valor propio para el estudio de la obra de Hoffmann en tanto testimonio y anticipación de sus opiniones estéticas y de su estilo literario. Este breve ensayo escrito en forma epistolar combina elementos narrativos con la crítica de arte -una mezcla típicamente hoffmanniana-. El elemento narrativo se concentra en el narrador ficticio, el monje de clausura, que refleja hiperbólicamente el aislamiento experimentado por el autor en Płock. Este personaje, por su profesión y su lenguaje sentimental, recuerda al narrador de los Efluvios cordiales de un monje amante del arte (1797), de Ludwig Tieck y Wilhelm Heinrich Wackenroder, aunque se diferencia por su humor y tono irónico. El monje hoffmanniano, recluido en su celda, gracias a las revistas literarias que le envían desde la capital, se entera de los debates recientes provocados por La novia de Mesina, el drama de Friedrich Schiller. Aquí se refleja un hecho histórico contemporáneo: a partir del estreno de esta obra el 19 de marzo de 1803 en Weimar, se desató una controversia respecto al uso del coro en el teatro, y los críticos se dividieron en dos bandos enfrentados. Desde el Freimüthigen, la revista editada por August von Kotzebue, en una reseña anónima de marzo de 1803 se cuestionó la pretensión de Schiller de restablecer el coro griego en un drama moderno. Esta posición fue contestada en mayo por August Klingemann desde la Zeitung für die elegante Welt, que asumió la defensa

2 Las traducciones son mías. La sigla SW remite a la edición de las obras completas de Hoffmann consignada en la Bibliografía. 
del dramaturgo. ${ }^{3}$ En este debate, el artículo de Hoffmann se alinea con la posición del Freimüthigen, donde aparece publicado. El argumento central que expone Hoffmann -a través de la pluma irónica y mordaz del monje- es que resulta absurdo reponer el coro griego porque se desconoce su modo de funcionamiento, en particular, se ignora cómo era la música de la época clásica. Aquí se anuncia ya la oposición de Hoffmann al anticuarianismo y la estilización del Clasicismo de Weimar, que desarrollará más tarde en sus principales ensayos de crítica teatral: Die Kunstverwandten (1817) y Seltsame Leiden eines Theater-Direktors (1819).

\section{Sobre esta edición}

"Escrito de un monje a su amigo en la capital” "Schreiben eines Klostergeistlichen an seinen Freund in der Hauptstadt") se publicó originalmente en Der Freimüthige oder Berlinische Zeitung für gebildete, unbefangene Leser, núm. 144 (9 de septiembre de 1803), pp. 573-574.

Traducimos a partir de la edición de Deutscher Klassiker de las obras completas de E.Th.A. Hoffmann que mencionamos en la bibliografía. El "Escrito de un monje" se encuentra en el primer tomo:

Frühe Prosa. Briefe. Tagebücher. Libretti. Juristische Schriften. Werke 1794-1813. Ed. de G. Allroggen et al. Frankfurt/M: Deutscher Klassiker, 2003, pp. 491-494.

También consultamos la edición de Aufbau:

Hoffmann, E.T.A. Gesammelte Werke in Einzelausgaben. Tomo 8: Letzte Erzählungen. Kleine Prosa. Nachlese. Ed. de H.-J. Kruse. Berlín, Weimar: Aufbau, 1983.

De acuerdo con esta segunda edición y a diferencia de la de Deutscher Klassiker, decidimos modificar la puntuación del original, que contenía solo dos párrafos (uno muy extenso al comienzo y uno breve al final), para facilitar la lectura.

3 El ensayo aclaratorio del propio Schiller, "Sobre el uso del coro en la tragedia", se publicó con la versión en libro de La novia de Mesina en junio de 1803, por lo que no pudo llegar a ser conocido por los primeros críticos (ni por Hoffmann, seguramente). El ensayo de Steinecke (2001) detalla estas discusiones previas sobre Schiller en la prensa, y es además el estudio más específico sobre este texto de Hoffmann. 


\section{Q Bibliografía}

" Hoffmann, E.T.A. (1985-2004). Sämtliche Werke in sechs Bänden. Ed. de H. Steinecke y W. Segebrecht. Frankfurt/M: Deutscher Klassiker.

"Safranski, R. (1984). E. T. A. Hoffmann. Das Leben eines skeptischen Phantasten. Múnich, Viena: Hanser.

"Steinecke, H. (2001). „Frohe Aspecten zur literarischen Laufbahn"? E.Th.A. Hoffmann in Ptock 1802-04. E.Th.A. Hoffmann-Jahrbuch, 9, 7-21. 


\section{Escrito de un monje a su amigo en la capital}

Te agradezco de corazón, mi querido amigo Theodor, que me hayas enviado tan pronto los libros encargados. El padre Prior tuvo la clemencia de enviarme la caja sin abrir a la celda, y me alegró que el hermano Vincentius, que me había visitado, estaba justamente yéndose cuando la recibí y abrí ansioso; él habría tomado con fastidio los muchos fascículos diversos que también me enviaste sin ningún encargo.

No te equivocas, mi querido amigo Theodor: también entre mis muros me gusta enterarme de cómo sigue todo en el mundo que abandoné para siempre, y por eso leí con mucho placer la Zeitung für die elegante Welt y el Freimüthigen, ${ }^{4}$ aunque algo me pareció totalmente singular y absurdo, lo que probablemente se deba a que en mi celda muchas circunstancias me son desconocidas.

Llegué a entender que los escritores de ambas revistas están enfrentados y tienen siempre opiniones muy diferentes. A veces son muy rudos y quieren defender su causa con exabruptos desagradables y calumnias mordaces. Eso no me gusta, y pensé en Su Reverencia el señor Prelado, quien una vez reprendió severamente al padre Adalbertus porque había insultado excepcionalmente al doctor Lutero en el sermón del día de San Antonio de Padua. El señor Prelado sostuvo: jeso significa más daño que provecho para la buena causa y es la señal de un carácter bruto y malvado!

Pero me conmoví completamente de alegría cuando leí que el célebre señor Schiller, quien, si no me equivoco, es el autor del bello poema que se llama Don Carlos, ${ }^{5}$ el cual leí cuando todavía me hallaba en el mundo, compuso un nuevo drama serio en el que introduce el coro a la manera de las antiguas tragedias griegas. Se llama La novia de Mesina.

Sabes, mi querido amigo Theodor, que siempre estudié apasionadamente la música y que no me conformé con el campo teórico superficial, el cual es suficiente para componer quizás una misa votiva, una víspera o un nuevo ofertorio para el día de un santo. Mi atención estaba orientada principalmente a la música de los antiguos, y siempre me sobrevenía un profundo dolor cuando leía en los

4 La Zeitung für die elegante Welt [Revista para el mundo elegante], de Leipzig, fue fundada en 1801 por el músico y escritor Karl Spazier, cuñado de Jean Paul, y existió hasta 1860. En sus inicios, fue afín al movimiento romántico. Der Freimüthige oder Berlinische Zeitung für gebildete, unbefangene Leser [El sincero o revista berlinesa para el lector culto e imparcial], editada desde 1803 por August Friedrich Kotzebue y August Kuhn era de tendencia contraria al romanticismo y el círculo de Goethe. Acerca de la discusión entre estas revistas a partir del estreno de La novia de Mesina, cf. nuestra Introducción.

5 Don Karlos. Infant von Spanien (1787). En una carta del 23 de enero de 1796, Hoffmann le cuenta a su amigo Theodor Gottlieb Hippel que está leyendo el Don Carlos por séptima vez, y que nada lo conmueve más que la amistad entre Posa y el Príncipe. 
escritores antiguos acerca de los efectos extraordinarios que esa música debe haber producido, y pensaba que el modo en que ella era ejecutada se perdió tan completamente. Comparé todo lo que pude encontrar en los antiguos escribas sobre la música y las representaciones teatrales de los antiguos griegos con ella asociadas; pero aún me resulta absolutamente oscuro qué se mantiene de la declamación de las tragedias griegas, que estaba indicada con notas, era acompañada de instrumentos musicales, y se llamaba melopeya, ${ }^{6}$ en comparación con aquello que ahora llamamos declamación y canto. ${ }^{7}$ Los coros de las tragedias griegas sin duda se aproximaron aún más al verdadero canto que la declamación del resto de los versos; eran interpretados por diferentes voces al unísono y acompañados de instrumentos musicales. Esto lo demuestra, entre otros, el pasaje del filósofo Séneca, donde se dice:

"Non vides quam multorum vocibus chorus constet, unus tamen ex omnibus sonus redditur. Aliqua illic acuta, aliqua gravis, aliqua media. Accedunt viris feminae, interponuntur tibiae, singulorum illic voces latent, omnium apparent etc."

Sin embargo, cómo era esto efectivamente puesto en obra, en qué medida se aproximaba o no la declamación del coro a la verdadera melodía, sobre esto no tengo una idea clara, y, hasta donde sé, hasta ahora nadie más logró rastrear la manera en que eso podría haberse realizado.

¡El importante descubrimiento había estado reservado para los señores eruditos en Weimar! Según leo, allí es representado el nuevo drama serio del señor Schiller que ya mencioné, e indudablemente la declamación fue indicada y es acompañada de instrumentos musicales. Cuéntame, querido amigo, si el propio señor Schiller, o alguien más, halló fortuitamente el rastro de los antiguos, y qué medios utilizó para iniciar a los actores y músicos en el misterio de la melopeya, que para nosotros se volvió completamente extraño.

Alguien escribe en el Freimüthigen que el coro fue hablado por siete hombres y que sonó como alumnos recitando su lección; y, en efecto, no puedo imaginarme nada más tonto e incongruente que a varias personas recitando versos en el teatro sin estar sujetas a aquella declamación anotada que las ciña a las marcas de tono y de ritmo. Pero sobre todo no puedo imaginarme que los eruditos señores de Weimar hayan concebido alguna vez la idea de devolverle el coro griego al teatro si no conocían en toda su extensión el modo de su representación en

6 En la Antigüedad, melopeya se refería a la invención de modos musicales o al arte de lograr un mayor efecto de los versos mediante la presentación melódica. Posteriormente, el término se usa en un sentido más general para referirse a la composición de melodías.

7 Hans-Joachim Kruse interpreta aquí una alusión crítica al estricto estilo de recitado promulgado por Goethe desde la dirección del teatro de Weimar, que se oponía al método libre de la escuela de Iffland en Berlín.

8 ¿¿No ves, acaso, de cuán diversas voces se compone un coro? Sin embargo, de todas resulta uno solo. En él una es aguda, otra grave, otra media, las femeninas se suman a las viriles, acompaña el son de las flautas, resultan imperceptibles las voces individuales, se impone el conjunto". Séneca, Epístolas morales a Lucilio (libros XI-XIII, ep. 84, 9). Trad. de I. Roca Meliá. Madrid: Gredos, 1989, tomo II, p. 53. 
tiempo de los antiguos; en la presentación que vio aquel hombre criticón, los tibiistas ${ }^{9}$ probablemente aún no habían practicado.

Escríbeme, además, mi querido amigo Theodor, si los flautistas acompañaron la declamación a lo largo de toda la pieza o solo apoyaron al coro, así como también si la tragedia se dio con máscaras y coturno. También estoy ansioso por saber qué efecto produjo el coro en los oyentes: si fueron conmovidos, o si a los actores les sucedió lo mismo que al difunto señor profesor Meibom, de quien se rio toda la corte de la reina Christina cuando comenzó a cantar un aria griega. Esto fue descortés, porque el hombre era muy erudito y de buenas intenciones, pero a veces tenía ocurrencias muy extravagantes, como podemos leer en muchos escritos. ${ }^{10}$

Finalmente, desearía que me instruyas sobre el motivo por el cual el señor Schiller no eligió para la tragedia, a la manera griega, una historia de héroes de la época antigua, sino una historia de la época moderna. Eso me resulta parecido a cuando aquí las monjas de Santa Úrsula visten en navidad al niño Jesús con el vestido de ceremonia que normalmente lleva la Virgen: siempre es demasiado largo y demasiado ancho, no se ajusta por ningún lado y no se ve bien.

Ahora bien, recién si la melopeya es restaurada y la gente supera lo inusual de la primera impresión, entonces saldrá bien el resto. Sin instrumentos musicales, sin declamación anotada, todo será solo una cháchara inútil.

La tragedia General Wallenstein, que el señor Schiller habría escrito en versos, y Los husitas ante Naumburg, que debe de ser una bella pieza, ya que discuten tanto sobre ella, ${ }^{11}$ serán estrenadas con la trágica flauta de bajo (tibia dextra), y las nuevas comedias del señor von Kotzebue, en versos, con la cómica flauta soprano (tibia siniestra). Me gustaría oír esto personalmente.

Adiós, mi querido amigo Theodor, rezo por ti a los santos y estoy etc.

G. D. ${ }^{12}$

9 Ironía de Hoffmann para referirse tanto a los flautistas modernos como a los intérpretes de la tibia, contraparte romana del aulos griego (un instrumento de viento usualmente doble, conformado por dos tubos con doble lengüeta).

10 Marcus Meibom (1620/21-1711), filólogo y matemático danés que se destacó en Königsberg y Leiden por la publicación de su Antiquae musicae auctores septem (Amsterdam, 1652). La anécdota referida por Hoffmann se registra en el Musicalisches Lexicon de J. G. Walther de 1732.

11 Die Hussiten vor Naumburg im Jahre 1432 (1803), de Kotzebue, también se presentó como una tragedia con coros. La discusión a la que alude Hoffmann se refiere a la parodia de esa obra escrita por Siegfried August Mahlmann publicada en la Zeitung für die elegante Welt, que a su vez fue contestada desde el Freimüthigen.

12 Iniciales de "Giuseppo Dori", seudónimo utilizado por Hoffmann el mismo año en una fantasía para piano que no se conserva. 